\title{
SELECTION OF EMPLOYEES BY MEANS OF QUANTITA- TIVE DETERMINATIONS
}

\author{
By Walter Dill Scott, Ph.D., \\ Department of Psychology, Northwestern University. \\ Non-Quantitative
}

Historically it has been the practice of many commercial and industrial organizations to recuperate their forces of employees by the employment of young boys and girls as helpers for menial service. The wages paid these employees were small and no careful selection was deemed essential. These helpers were given no systematic instruction. There was no plan in routing them from one position to another in order that they might learn the whole or any significant part of the business. Promotion from the ranks was insisted upon in many instances even though no attention was given to preparation for such promotions. The children who accepted such positions were frequently those who had already failed in school. Their failures were mainly due to lack of interest in school work and this lack of interest could usually be traced to a lack of native intellectual ability. The ranks were, therefore, filled by many who had already proved themselves to be incompetents. No attempt was made to make the most of this defective native ability and yet the executive assumed that the higher positions must be filled by recruits from this untrained group of intellectual weaklings. This absurd method of selection is still in existence in many firms.

In certain houses the selection was based upon an inadequate estimation of the technical ability of the applicant. This ability was judged by the number and nature of positions previously held or by a sample performance on the part of the applicant. This sample performance in some cases meant a try-out for one or more days.

In some instances the native ability of the applicants has been estimated but inadequately. This judgment was based on the ability of the applicant as expressed in general terms by friends or by some statement as to the grade in school to which the applicant 
had attained. Not infrequently the statements as to the intellectual ability were supplemented by general statements as to the moral character and health.

In all the methods thus far referred to no records were kept of the findings of the employer and, in fact, no records could be kept because none of the findings were reduced to quantitative determinations or any sort of terms of measurement.

\section{Quantitative Determinations}

During the last two years the writer has been attempting to reduce to quantitative determination all methods heretofore used in selecting employees and to supplement these where necessary.

One factor frequently recognized in the selection of employees is that of the Previous Record, but unfortunately this very important factor is frequently regarded as useless because of the impossibility of securing trustworthy and useable information from previous employers. In attempting to secure more trustworthy and useable information the following blank has been devised and used successfully.

\section{Dear Sir:}

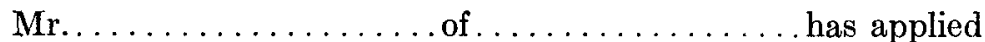
to us for a position as salesman and given you as reference. He

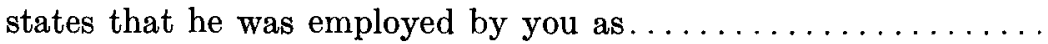
for a period.

Will you please advise whether this information is correct?

Why did the applicant leave'your employment?

Please place a check mark in the space below that indicates the character of his service:

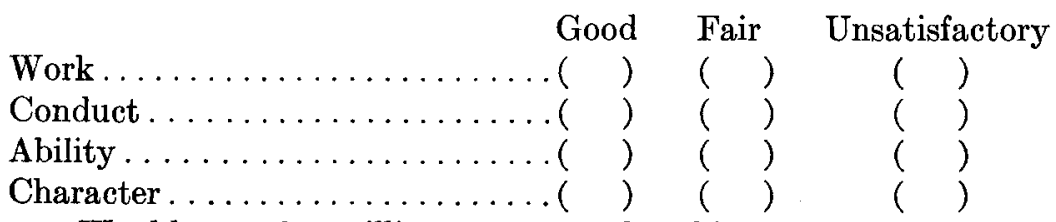

Would you be willing to re-employ him? 
Would you recommend him for the position applied for?

Out of ten men filling the position which the applicant held with you, what would be his comparative rank?

(If he would be the best, please mark his rank 1 ; if the poorest, please mark his rank 10; this estimate is of course only an approximation, but we will greatly appreciate your best judgment in the matter.)

\section{Sincerely yours,}

This blank does not encourage the former employer to use general and meaningless expressions, but whatever he says may be readily used in quantitative determinations. Unfortunately a great flexibility seems necessary in the use of the blank but where possible a demand is made that this blank should be filled out in full by the three last employers if the applicant has had that many. With these blanks before him the employment manager can change the data to a percentage basis. For instance: if all the previous employers fill in all the blanks under "Good" and put a (1) in the last paragraph, the applicant is then given 100 per cent on Previous Record. Corresponding percentages are given for all the various combinations found in the blank.

The Physical Condition of the applicant is judged by an experienced physician who makes his reports in quantitative terms. His viewpoint is not that of longevity but of health and vitality in relation to the service to be performed. The applicant whose physical organism seems best adapted for the type of work contemplated would be given 100 per cent on physical condition. Anything less than an ideal physical organism is graded less than 100 per cent depending upon the degree of defectiveness. Although experiments have been carried on, as here indicated, satisfactory results have not yet been' secured, but, at least, a good beginning has been made.

The Native Intellectual Ability of the applicant is determined by means of a series of mental tests which test, not the learning, but the native ability. The series of tests employed are adjusted to the general type of applicants and the nature of the service to be rendered. For some positions emphasis is placed on inventive ability, on others tact, on others initiative, on others quickness of 
thought, etc. The applicant is then graded by a percentage figure indicating the native ability in each of the qualities under consideration; as well as by a single figure to express the entire native intellectual ability so far as tested. The blank here reproduced is one that has been used with good success in testing salesmen for several organizations. The applicant is given 100 per cent in speed if he completes the blank in ten minutes; 0 per cent if he completes it in 60 minutes; 50 per cent if he completes it in 35 minutes, etc. He is given a grade of 100 per cent in accuracy if he makes no errors. Correspondingly lower grades are given for various mistakes or numbers of mistakes. No attempt has been made to determine definitely the particular mental ability tested by this blank. Although its use has been discontinued because of improved substitutes it might well be given as a fair sample. It was never given except as one of a series of tests, as no adequate conclusion can be based on the findings of a single test.

\section{TEST I.}

Read the General Directions before you do anything else.

General Directions:

Do what the printed instructions tell you to do.

Do not ask the examiner any questions about the examination.

Do not ask any other person who is taking the examination any questions or watch anyone to see what he or she does.

Work as rapidly as you can without making any mistakes.

If you do make a mistake, correct it neatly.

Do 1 first, then 2, then 3 , and so on.

1. Write your name and permanent address here.

Instructions for 2, 3 and 4:

After each word printed below you are to write some word, according to the further directions. Write plainly, but as quickly as you can. If you cannot think of the right word in about 3 seconds, go ahead to the next.

2. Write the opposites of the words in this column, as shown in the first three.

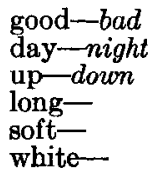

3. Write words that fit the words in this column, in the way shown in the first three.

drink-water

ask-questions

subtract-numbers

sing-

build-

wear-
4. Write words that tell what sort of a thing each thing named is, as shown in the first three.

lily-flower

blue-color

diamond-jewel

oak-

measles-

July- 


$\begin{array}{lll}\text { far- } & \text { shoot- } & \text { shark- } \\ \text { up- } & \text { scold- } & \text { quinine- } \\ \text { smooth- } & \text { win- } & \text { beef- } \\ \text { early- } & \text { answer- } & \text { canoe- } \\ \text { dead- } & \text { weave- } & \text { banana- } \\ \text { hot- } & \text { wink- } & \text { Atlantic- } \\ \text { asleep- } & \text { mend- } & \text { Alps- }\end{array}$

5. Add 17 to each of these numbers. Write the answers as shown in the first three.

$\begin{array}{lll}29 & 46 & \\ 18 & 35 & \\ 60 & 77 & \\ 64 & & 61 \\ 49 & & 71 \\ 62 & & 33 \\ 57 & & 38 \\ 68 & & 28 \\ 74 & & 65 \\ 53 & & 41 \\ 67 & & 50 \\ 25 & & 42 \\ 40 & & 58\end{array}$

6. Get the answers to these problems as quickly as you can.

1. What number minus 16 equals 20 ?

2. A man spent $\frac{2}{3}$ of his money and had $\$ 8$ left. How much had he at first?

3. At 15 cents a yard, how much will 7 feet of cloth cost?

4. A man bought land for $\$ 100$. He sold it for $\$ 120$, gaining $\$ 5$ an acre. How many acres were there?

5. If $\frac{3}{4}$ of a gallon of oil costs 9 cents, what will 7 gallons cost?

7. Write opposites for this column, as shown in the first three. If you cannot think of the right word in about 10 seconds, go ahead to the next.

bravery-cowardice

friend-enemy

true-false

serious-

grand-

to win-

to respect-

frequently-

to lack -

apart-

stormy -

motion-

forcible-

straight-

to hold-

after-

to float-

rough-

to bless-

to take-

exciting-

clumsy-

unless-
8. Write in each line a fourth word that fits the third word in that line in the way that the second word fits the first, as shown in the first three lines. If you cannot think of the right word in about 10 seconds, go ahead.

color-red; name-John

page-book; handle-knife

fire-burns; soldiers-fight

eye-see; ear-

Monday-Tuesday; April-

do-did; see-

bird-sings; dog-

hour-minute; minute-

straw-hat; leather-

cloud-rain; sun-

hammer-tool; dictionary-

uncle-aunt; brother-

dog-puppy; cat-

little-less; much-

wash-face; sweep-

house-room; book-

sky-blue; grass-

swim-water; fly-

once one; twice-

cat-fur; bird-

pan-tin; table-

buy-sell; come-

oyster-shell; banana- 
9. Do what it says to do as quickly as you can, but be careful to notice just what it does say.

With your pencil make a dot over any one of these letters $F H I J$, and a comma after the longest of these three words: boy mother girl. Then, if Christmas comes in March, make a cross right here... . but if not, pass along to the next question, and tell where the sun rises.......... If you believe that Edison discovered America, cross out what you just wrote, but if it was some one else, put in a number to complete this sentence: " $\mathrm{A}$ horse has .... feet." Write yes, no matter whether China is in Africa or not ....; and then give a wrong answer to this question: "How many days are there in the week?" . . . . . . . . . Write any letter except $\theta$ just after this comma, and then write no if 2 times 5 are $10 \ldots$. Now, if Tuesday comes after Monday, make two crosses here.....; but if not, make a circle here...... or else a square here...... Be sure to make three crosses between these two names of boys: George. . ......... Henry. Notice these two numbers: $\beta, \bar{\delta}$. If iron is heavier than water, write the larger number here........, but if iron is lighter, write the smaller number here...... Show by a cross when the nights are longer: in summer? ... in winter? ..... Give the correct answer to this question: "Does water run uphill?"......... and repeat your answer here....... nothing here $(5+7=\ldots \ldots)$, unless you skipped the preceding question; but write the first letter of your first name and the last letter of your last name at the ends of this line:.......

10. Place in the bracket preceding each English proverb the number of the African proverb to which the English proverb corresponds in meaning.

English Proverbs.

African Proverbs.

( ) Married in haste, we 1, One tree does not make a forest. repent at leisure.

( ) Answer a fool accord- 2. "I nearly killed the bird." No one can eat ing to his folly.

( ) One swallow does not make a summer.

( ) First catch your hare.

( ) Adding insult to injury.

( ) Curses come home to roost. "nearly" in a stew.

3. Full-belly child says to hungry-belly child, "Keep good cheer."

4. Distant firewood is good firewood.

5. Ashes fly in the face of him who throws them.

6. If the boy says he wants to tie the water with a string, ask him whether he means the water in the pot or the water in the lagoon.

( ) Distance lends enchantment to the view

7. The ground-pig said: "I do not feel so angry with the man who killed me as with the man who dashed me on the ground afterward."

( ) We can all endure the misfortunes of others.

8. Quick loving a woman means quick not loving a woman.

Just as soon as you finish, give your paper to the examiner so as to get credit for having completed the work before time was called.

The Technical Ability of the applicant is reduced to quantitative determinations by various devises. Applicants for statistical positions are tested by means of the following statistical blank. This blank was devised for and used by an organization having a large amount of statistical work of the general type here indicated. The applicant is given 100 per cent in speed if he completes the task in 25 minutes and he is discredited 2 per cent for each minute thereafter. He is given 100 per cent in accuracy if he makes no mistakes. Five per cent is deducted from his grade for each error.

His handwriting is determined by the appearance of his copy 
of the names and the numbers which immediately follow them. This transfer to quantitative determinations is made by means of the Ayres' Scale for Handwriting.

NAME

Perform all the additions and multiplications called for in the following problems:

AdDition EXamples.

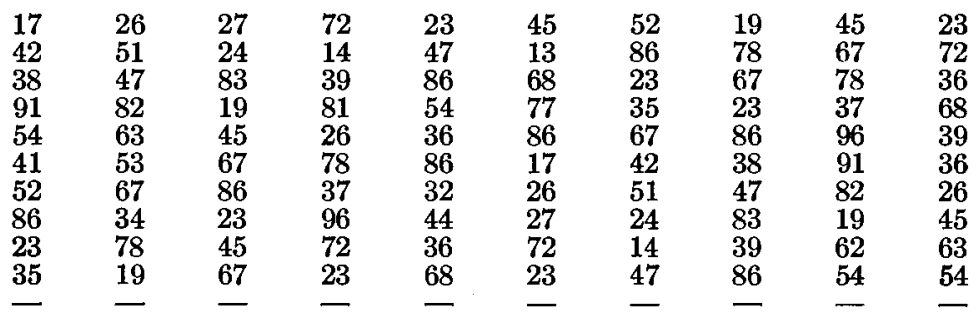

MUltiplication Exampleg. 
Transcribe this page onto the next page. Make every figure and letter so that it can be read easily.

\begin{tabular}{|c|c|}
\hline W. H. Abelmann & 9685247 \\
\hline 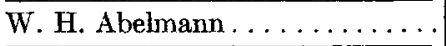 & 1352680 \\
\hline Edward Adam.............. & 573828 \\
\hline 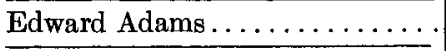 & 753823 \\
\hline$\overline{\mathrm{W}} \mathrm{m}$. Anderson ............. & 56308 \\
\hline Wm. Anderson . . . . . . . . . . . & 56308 \\
\hline Peter Andersen ................ & 48365 \\
\hline Peter Anderson ............. & 48365 \\
\hline Benj. Andruskowitch ......... & 100085 \\
\hline Thomas Andruskoweich........ & 110085 \\
\hline John Anglin................ & 842745 \\
\hline Thomas Anglim............. & 842745 \\
\hline E. J. Atchison .............. & 960261 \\
\hline 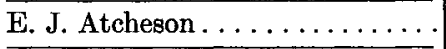 & 960261 \\
\hline L. A. Auston ............... & 960162 \\
\hline Bachalc $W m \ldots \ldots \ldots \ldots \ldots$ & 372819 \\
\hline 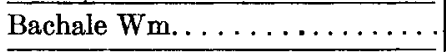 & 272819 \\
\hline J. Balderton . . . . . . . . . . & 100278 \\
\hline$\ldots \ldots \ldots \ldots$ & 102278 \\
\hline August Bansback ............. & 26710 \\
\hline Chas Banschback ........... & 95525 \\
\hline Chas Barnett ............... & 52617 \\
\hline 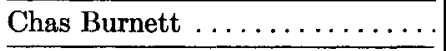 & 82910 \\
\hline Henry Burnett. . . . . . . . . . & 111456 \\
\hline Thomas Burrett. ............. & 867543 \\
\hline Andrew Bartoli .............. & 142567 \\
\hline Paulina Bartold ............ & 55555 \\
\hline John G. Battershill. .......... & 42890 \\
\hline A. Batterson ............. & 81392 \\
\hline A. E. Bauermeister ............ & 185 \\
\hline Henry Baumeister . . . . . . . . & 67540 \\
\hline Wallace Beaman............. & 10025 \\
\hline T. Baeman . . . . . . . . . . . & 56470 \\
\hline
\end{tabular}



lines.

Transcribe the preceding page onto this page as is indicated on the first three

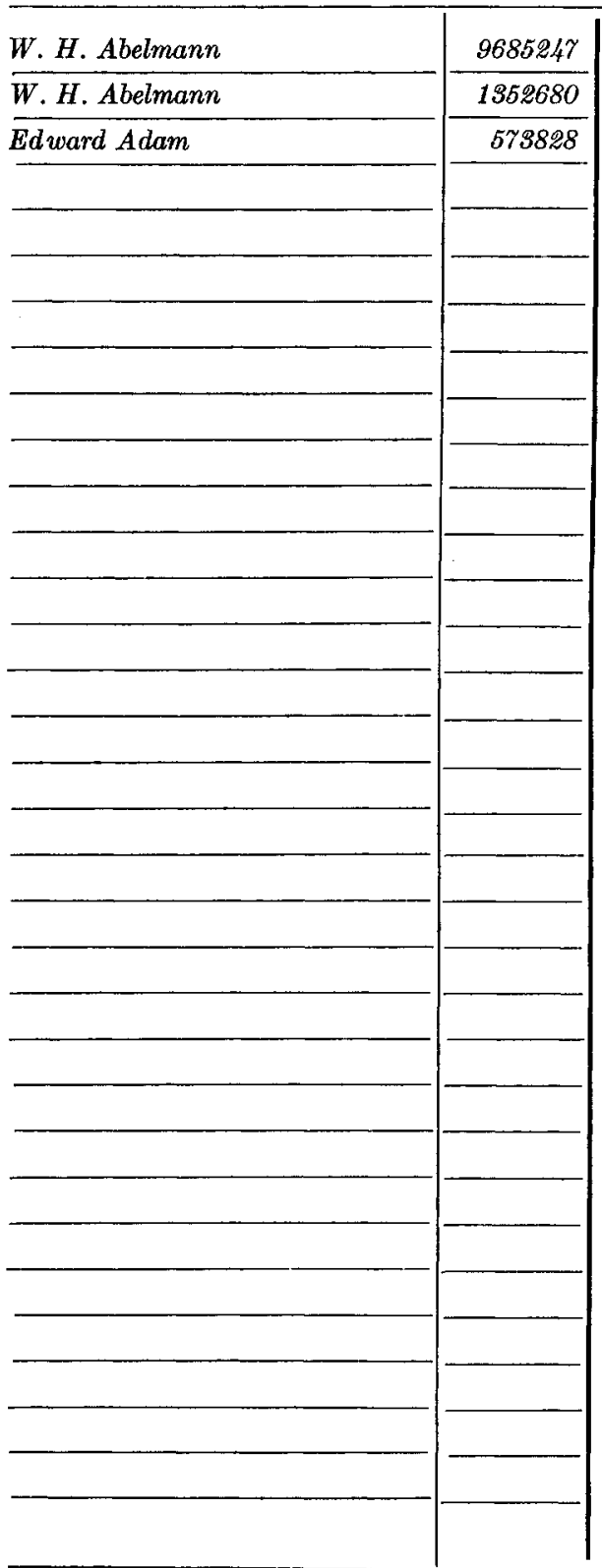


Look at each pair of numbers. Make a cross after every pair where the two numbers are not alike (as shown here):

$\begin{array}{lrrlllll} & & 907328 & 907329 \times & 760023 & 760023 & & \\ & & 216540 & 216540 & 297500 & 297600 \times & & \\ & & 856728 & 847628 \times & 107910 & 107910 & & \\ 286090 & 289060 & 329865 & 329865 & 702645 & 702645 & 908701 & 908701 \\ 976534 & 976534 & 574052 & 574052 & 610124 & 611124 & 116872 & 116872 \\ 821004 & 821004 & 738216 & 783216 & 503763 & 503763 & 805794 & 805794 \\ 598362 & 598362 & 895422 & 895422 & 921821 & 921821 & 248067 & 248067 \\ 774819 & 747189 & 635767 & 635767 & 869030 & 863090 & 753915 & 753915 \\ & & 700035 & 70035 \times & 864271 & 864271 & & \\ 612345 & 612345 & 942424 & 942424 & 274502 & 274502 & 310283 & 210283 \\ 400705 & 400005 & 432615 & 432615 & 485734 & 485734 & 601943 & 601943 \\ 309268 & 309268 & 133002 & 133302 & 697685 & 697685 & 439250 & 439250 \\ 978882 & 978882 & 325961 & 325961 & 806960 & 806960 & 583622 & 583922 \\ 538620 & 538620 & 473820 & 473820 & 378117 & 378171 & 927474 & 927474 \\ 700214 & 700214 & 562143 & 562942 & 145900 & 145900 & 845825 & 845825 \\ 800000 & 800000 & 997723 & 997723 & 238392 & 238392 & 646935 & 646935 \\ 613579 & 613572 & 714926 & 714926 & 39273 & 39273 & 767561 & 767561 \\ 200140 & 200140 & 831125 & 831125 & 901284 & 901284 & 385000 & 380000 \\ 531251 & 531251 & 642030 & 642030 & 861357 & 861357 & 466799 & 467699 \\ 732124 & 732124 & 214728 & 214728 & 450549 & 490594 & 674887 & 674877 \\ 414362 & 414362 & 192563 & 192365 & 546457 & 546457 & 589746 & 589746 \\ 349093 & 349093 & 643215 & 643245 & 673860 & 673860 & 291968 & 291968 \\ 955785 & 95785 & 571326 & 571326 & 896812 & 896812 & 109590 & 109590 \\ 267682 & 267682 & 800026 & 800026 & 782933 & 782833 & 323041 & 323041 \\ 127003 & 127030 & 304349 & 304349 & 638542 & 638542 & 347391 & 347391 \\ 281114 & 281114 & 515420 & 515420 & 596169 & 596169 & 252824 & 252824 \\ 620259 & 620259 & 915656 & 915656 & 405970 & 405970 & 861753 & 861735 \\ 731622 & 736122 & 767817 & 787617 & 924441 & 92441 & 486798 & 486798 \\ 443378 & 443378 & 821738 & 821738 & 133508 & 133508 & 719060 & 719060\end{array}$

The technical ability of the applicant for a selling position is determined by means of a selling performance as indicated by the following "Instruction to Applicants" blank. Each "Buyer" estimates the selling performance on a percentage basis. The estimates of these several "Buyers" are combined into a single grade expressive of the applicant's technical ability as a salesman. Whatever the technical ability is, it must be expressed in quantitative terms before it becomes serviceable.

\section{Instruction to Applicants}

In Room A is a merchant who is to be regarded as a "buyer." You are to enter Room A, introduce yourself to Merchant A, and try to sell him some kind of merchandise. You will spend 
five minutes with Mr. A, then pass on to Room B and repeat your selling talk to Merchant B. You will keep this up till you have called on all the "buyers."

You may sell any line of merchandise. The following are examples: automobiles, breakfast food, clothing, fountain pens, life insurance, office supplies, real estate, rubber goods, sporting goods, tobacco, typewriters, etc.

You may make the same talk to each "buyer." If you decide to sell an automobile, then you may assume that each of the merchants is an automobile dealer. If you decide to sell a breakfast food, then assume that each "buyer" is a grocer, etc.

Present your merchandise for five minutes in such a way that the "buyer" will actually want to purchase your line. Sell as you would if the "buyer" were a real prospective.

Prepare your line of talk in advance!

The personality of the applicant is an important factor but one particularly hard to reduce to quantitative determinations. The method which the writer has been employing is to have several "Interviewers" pass judgment upon the applicant. This judgment is based on personal appearance, tact, industry, promise of usefulness to the company, etc. Whatever the qualities are that are judged the "Interviewers" must summarize their judgment in a single figure, ordinarily, but not necessarily, a percentage figure. The judgments of all the "Interviewers" are then combined into a single figure expressive of the personality of the applicant.

Some of these fine quantitative determinations cited are of more importance than others but all must be combined into a single figure. This may be done by weighing the different figures according to their relative importance. The advantage of these different quantitative determinations and of the one summarized quantitative determination is that it makes it possible to compare these original estimates with later success. The adequacy or inadequacy of the parts of the test or of the whole system of testing can thus be accurately determined. In this way any particular test is eliminated if the prognosis based on that test fails to correspond to the later history of the worker. The chief advantage of the methods indicated above is not in having the right methods of testing to start with, but in having a method of handling results which make it possible to eliminate the unsuccessful factors in the 
test and to strengthen those factors which are successful. This enables us to develop tests in the line of success as indicated by practice and not within the line which might be assumed by theory. If this method should claim the prerogative of "scientific," it would base the claim not upon the fact that it utilizes the findings of the medical examiner, nor upon the fact that it utilizes the findings of experimental psychologists, but upon the fact that it reduces the entire process to measurable terms which may be checked up by known and recognized standards.

\section{THE USE OF MENTAL TESTS IN VOCATIONAL GUIDANCE ${ }^{1}$}

\section{By Guy Montrose Whipple, Professor of Education, University of Illinois.}

Mr. Chairman, Ladies and Gentlemen:

When Mr. Davis, just a few days ago, asked me to take the place of Dr. Bassett, who has been unfortunately prevented by illness from filling the engagement assigned him on your program, I consented with the understanding that the presiding officer in introducing me would apologize for the unavoidably hasty preparation and somewhat too sketchy character of my offering. I am unable to present to you anything like a comprehensive survey of the application of mental tests to vocational guidance, but have limited myself to presenting a few of the general principles that seem to me operative in that application and to illustrating, by reference to results recently obtained from a single mental test, something of the service that tests may render in the direction of diagnosing degree of general native ability.

I suppose there is little doubt that the majority of occupations are chosen by chance, which is equivalent to saying that they are not chosen at all. A considerable fraction, I suppose probably a majority, of those gainfully employed might, under very slightly changed conditions, have been in some other vocation than the one

${ }^{1}$ This paper was read by the author before the National Vocational Guidance Association at Detroit, February 22, 1916. 